\title{
Lipophilicity Study of 1-(Benzofuran-2-yl)ethan-1-one Oxime and its Substituted $O$-Benzyl Ethers
}

\author{
Tomasz Kosmalski, ${ }^{*, \#}$ Renata Studzińska, ${ }^{*, \#}$ Matgorzata Redka, Robert Pluskota and \\ Bożena Modzelewska-Banachiewicz.
}

\author{
Department of Organic Chemistry, Faculty of Pharmacy, Collegium Medicum in Bydgoszcz, \\ Nicolaus Copernicus University in Toruń, Jurasza 2, 85-089 Bydgoszcz, Poland
}

\begin{abstract}
Heterocyclic oxime ethers play a significant role in organisms due to their biological activity. Lipophilicity is an important parameter that may affect biological activity of the compounds 1-(benzofuran-2-yl)ethan-1-one oxime and its nine biologically active ethers. The relationship between the structure and lipophilicity parameters ( $\log \mathrm{k}_{\mathrm{w}}$ values) of the ten compounds is here described. Reversed phase high performance liquid chromatography (RP-HPLC) method was used having methanol, 2-propanol and acetonitrile as organic modifiers of the mobile phases. Both experimental $\left(\log \mathrm{k}_{\mathrm{w}}\right)$ and calculated $(\log \mathrm{P})$ parameters showed to be strongly positively correlated. The weakest correlation with all the data was for the $\log \mathrm{k}_{\mathrm{w}}$ methanol. For all of analyzed compounds, $\log \mathrm{k}_{\mathrm{w}}$ values are smaller than 5 (except for analyses carried out in methanol), and this result corresponds to the Lipinski's rule in the range of lipophilicity. Therefore, in the case of their use as drugs, they will be probably active after oral application.
\end{abstract}

Keywords: lipophilicity, oxime ethers, high-performance liquid chromatography, biological activity

\section{Introduction}

Heterocyclic compounds represent a very broad class of organic compounds essential in chemistry, pharmacy and chemical industries. ${ }^{1}$ The heterocyclic systems are part of many drugs and determine their activity. ${ }^{2}$ Benzofuran ring is one of the basic oxygen heterocyclic rings. Many benzofuran derivatives are compounds having diverse biological activity, inter alia: antihyperglycemic, analgesic, anti-inflammatory, antimicrobial, antitumor, antidiabetic, antidepressant and others. ${ }^{3,4}$

Oxime ethers are interesting compounds due to their diverse biological activities. The compounds exhibit anticancer, ${ }^{5}$ anticonvulsant, ${ }^{6}$ antimicrobial, ${ }^{7}$ antiparasitic ${ }^{8}$ and acaricidal ${ }^{9}$ activities. The most popular compound that contains oxime ether group is an oxiconazole (Figure 1). Oxiconazole is an effective antifungal drug used in treatment of mycosis. Benzofuran oximes and oxime ethers, for example (3-methyl-benzofuran-2-yl) ketoximes ${ }^{10}$ and benzyl oxime ether dinaphtho[2,1-b] furan2-yl-methanone, have the high antimicrobial activity. ${ }^{11}$

*e-mail: tpkos@wp.pl; rstud@cm.umk.pl

\#Tomasz Kosmalski and Renata Studzińska have equally contributed to the present paper and should be considered the first authors.
Some oxime ethers of bisbenzofuran-2-yl-methanone also exhibit specific antimicrobial activities. ${ }^{12}$ In our study, we combined benzofuran ring with oxime ether moiety. We supposed the resulting benzyl oxime ethers of 2-acetylobenzofuran may have high antimicrobial activity. The oxime ethers obtained by us that contained the benzofuran system and $O$-benzyl substituents (as in an oxiconazole) displayed significant antimicrobial activity. ${ }^{13}$<smiles>O=C(O[Na])ON=C(Cn1ccnc1)c1ccc(Cl)cc1Cl</smiles>

Figure 1. Structure of the oxiconazole.

The transport of substances through the lipid membranes is the first step of evaluating their usefulness as a drug. Therefore, the products of organic synthesis, in addition to the defined biological activity, should be tested to determine the solubility in the lipid phase. 
Lipophilicity, which describes the solubility of the drugs in lipids, is the most important parameter to expect biological activity of the compound. It is expressed as a partition coefficient in octanol/water system $(\mathrm{P})$ or, more often, its decimal logarithm $(\log \mathrm{P})$. The higher the partition coefficient $\mathrm{P}$, the higher similarity of the drug to the lipid membranes and better resorption. ${ }^{14}$

The Lipinski's rule-of-five (which describes molecular properties important for drug pharmacokinetics in the human body) says that $\log \mathrm{P}$ of a orally active drug is equal or smaller than $5 .{ }^{15}$ One method of determination of lipophilicity is based on chromatography. Most often, reversed phase high performance liquid chromatography (RP-HPLC) and reversed phase thin layer chromatography (RP-TLC) techniques are used because are simple to implement and provide accurate results. ${ }^{16}$

In the present work, we determined chromatographically lipophilicity parameters of oxime of 1-(benzofuran-2-yl) ethan-1-one and its nine antimicrobial active heterocyclic ethers using RP-HPLC methods and compared them with computed $\log \mathrm{P}$ values. In our previous work, ${ }^{13}$ we reported the synthesis of the series of the novel heterocyclic oxime ethers (2-10) via the reaction of oxime $\mathbf{1}$ with substituted benzyl bromides and potassium carbonate in acetone with high yields.

\section{Experimental}

The oxime $\mathbf{1}$ and oxime ethers (2-10) were synthesized according to publication (Table 1). ${ }^{8}$ Lipophilicity parameters were determined by chomatographic method, using RP-HPLC as follow. ${ }^{17,18}$

\section{Reversed-phase HPLC}

The HPLC experiments were performed on the Shimadzu HPLC system (Japan) equipped with solvent delivery pump LC-20AD, UV-Vis detector model SPD-20A, degasser model DGU-20A5, a column oven model CTO-20A, and a column Superspher ${ }^{\circledR} 100$ RP-18 $(4 \mu \mathrm{m})$ (Merck, Germany). Mobile phase methanol/water, 2-propanol/water and acetonitrile/water varied in the ratios. The solvents were methanol, 2-propanol, acetonitrile and water for HPLC from POCH (Poland). Organic modifier concentrations (expressed as volume fraction $\mathrm{v} \mathrm{v}^{-1}$ ) varied in the range from 0.60 to 0.95 in constant steps of 0.05 . Compounds were dissolved in suitable organic solvent $\left(1 \mathrm{mg} \mathrm{mL}^{-1}\right)$. Sample injection volume was $10 \mu \mathrm{L}$. The time for dead volume $\left(\mathrm{t}_{\mathrm{M}}\right)$ was measured by uracil. The capacity factor (k) was calculated by relationship:

$\mathrm{k}=\frac{\mathrm{t}_{\mathrm{R}}}{\mathrm{t}_{\mathrm{M}}}-1$

where $t_{R}$ is retention time and $t_{M}$ time for dead volume.

The linear relationship between $\log \mathrm{k}$ values and the concentration of the organic modifier in the mobile phase were calculated by relationship:

$\log \mathrm{k}=\log \mathrm{k}_{\mathrm{w}}+\mathrm{S} \phi$

where $\log \mathrm{k}_{\mathrm{w}}$ value is extrapolated to zero organic modifier concentration, $\phi$ is organic modifier concentration in the mobile phase (in volume fraction $\mathrm{v} \mathrm{v}^{-1}$ ), $\mathrm{S}$ is the slope of

Table 1. The lipophilicity parameters $\left(\log \mathrm{k}_{\mathrm{w}}\right.$ ) determined from RP-HPLC experimental values

\begin{tabular}{|c|c|c|c|c|c|c|c|c|c|c|c|}
\hline \multirow{2}{*}{$\begin{array}{l}\text { Organic } \\
\text { modifier }\end{array}$} & \multirow{2}{*}{$\begin{array}{c}\text { Lipophilicity } \\
\text { parameter }\end{array}$} & \multicolumn{10}{|c|}{ Compound } \\
\hline & & 1 & 2 & 3 & 4 & 5 & 6 & 7 & 8 & 9 & 10 \\
\hline \multirow{4}{*}{ Methanol } & $\log k_{w}$ & 2.50 & 5.83 & 5.81 & 4.84 & 5.59 & 5.38 & 6.06 & 4.89 & 2.50 & 4.91 \\
\hline & $-\mathrm{S}$ & 3.402 & 6.187 & 6.344 & 5.320 & 5.903 & 5.756 & 6.215 & 5.424 & 3.405 & 5.418 \\
\hline & $\phi_{0}$ & 0.734 & 0.943 & 0.916 & 0.910 & 0.946 & 0.935 & 0.976 & 0.902 & 0.735 & 0.907 \\
\hline & $\mathrm{R}^{2}$ & 0.988 & 0.994 & 0.994 & 0.981 & 0.993 & 0.995 & 0.994 & 0.993 & 0.993 & 0.992 \\
\hline \multirow{4}{*}{ Isopropanol } & $\log \mathrm{k}_{\mathrm{w}}$ & 0.94 & 2.45 & 2.27 & 2.02 & 2.25 & 2.16 & 2.54 & 2.03 & 2.18 & 1.39 \\
\hline & $-\mathrm{S}$ & 2.279 & 3.172 & 3.278 & 2.886 & 2.983 & 2.931 & 3.139 & 2.984 & 2.961 & 2.215 \\
\hline & $\phi_{0}$ & 0.413 & 0.772 & 0.691 & 0.700 & 0.753 & 0.736 & 0.809 & 0.680 & 0.738 & 0.628 \\
\hline & $\mathrm{R}^{2}$ & 0.997 & 0.966 & 0.992 & 0.995 & 0.995 & 0.997 & 0.993 & 0.997 & 0.981 & 0.977 \\
\hline \multirow{4}{*}{ Acetonitrile } & $\log \mathrm{k}_{\mathrm{w}}$ & 1.60 & 4.57 & 3.62 & 3.16 & 3.45 & 3.38 & 3.75 & 3.21 & 3.31 & 3.18 \\
\hline & $-\mathrm{S}$ & 2.654 & 5.324 & 4.122 & 3.697 & 3.810 & 3.781 & 3.930 & 3.779 & 3.724 & 3.775 \\
\hline & $\phi_{0}$ & 0.604 & 0.857 & 0.878 & 0.855 & 0.907 & 0.895 & 0.955 & 0.849 & 0.889 & 0.842 \\
\hline & $\mathrm{R}^{2}$ & 0.860 & 0.996 & 0.995 & 0.998 & 0.997 & 0.998 & 0.995 & 0.996 & 0.938 & 0.994 \\
\hline
\end{tabular}

$\log \mathrm{k}_{\mathrm{w}}: \log \mathrm{k}$ value extrapolated to zero organic modifier concentration; $\mathrm{S}$ : slope of the regression curve; $\phi_{0}:$ lipophilicity parameter $\left(\phi_{0}=\log \mathrm{k}_{\mathrm{w}} / \mathrm{S}\right)$; $\mathrm{R}^{2}$ : coefficient of determination. 
<smiles>[R]ON=C(C)c1cc2ccccc2o1</smiles>

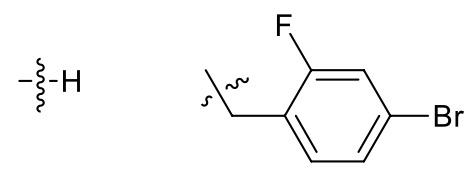

1

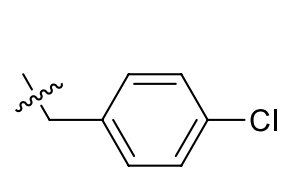

6
2

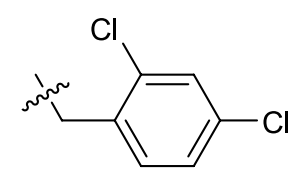

7

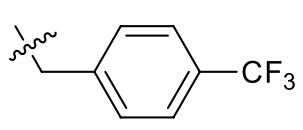

3

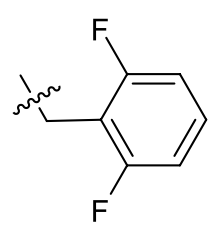

8

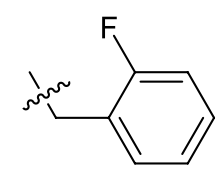

4

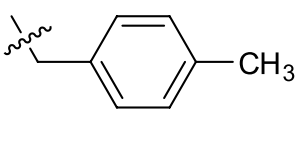

9

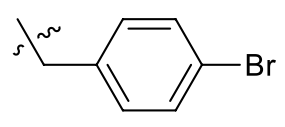

5

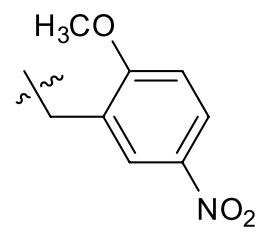

10

Figure 2. Structures of compounds 1-10.

the regression curve. All experiments were performed at $25^{\circ} \mathrm{C}$. The lipophilicity parameter $\left(\phi_{0}\right)^{16,19}$ was calculated by relationship

$\phi_{0}=-\frac{\log \mathrm{k}_{\mathrm{w}}}{\mathrm{S}}$

\section{Results and Discussion}

The $\log \mathrm{k}_{\mathrm{w}}$ lipophilicity parameters were determined for 1-(benzofuran-2-yl)ethan-1-one oxime $\mathbf{1}$ and its nine potentially active ethers $\mathbf{2 - 1 0}$ of the structure in Figure 2. Methanol, isopropanol and acetonitrile were the organic modifiers.

The linear dependence between $\log \mathrm{k}$ values and concentration of organic modifier in the eluent was observed. High values of coefficients of determination $\left(\mathrm{R}^{2}=0.938-0.998\right)$ were observed for all organic modifiers in a wide range of organic solvents concentration in mobile phase. The exception was the compound $\mathbf{1}$ in acetonitrile $\left(R^{2}=0.860\right)$. The lipophilicity parameters $\log \mathrm{k}_{\mathrm{w}}$ were determined by extrapolation, and $\phi_{0}$ parameters by interpolation (Table 1).

For the examined compounds, the $\log \mathrm{k}_{\mathrm{w}}$ values were lowest using isopropanol as the organic modifier and the highest values in methanol/water system. The exception was compound 9 for which the highest value $\log \mathrm{k}_{\mathrm{w}}$ was obtained in acetonitrile/water system (Figure 3).

The lowest value of $\log \mathrm{k}_{\mathrm{w}}$ was observed for oxime $\mathbf{1}$ $\left(\log \mathrm{k}_{\mathrm{w}}<2.5\right)$, which means that it is the most hydrophilic compound. The presence of $\mathrm{OH}$ group in the molecule of oxime was indicated for this. The substitution of a

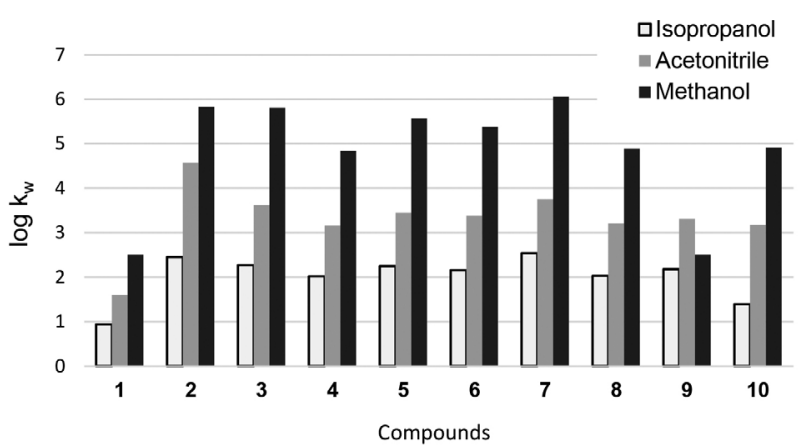

Figure 3. The relationship between $\log \mathrm{k}_{\mathrm{w}}$ values of compounds 1-10 depending on the organic modifier.

hydrogen atom in the oxime $\mathrm{OH}$ group by the substituted benzyl group increased the $\log \mathrm{k}_{\mathrm{w}}$ parameter. The presence of substituents at the 4-position of the aromatic ring (compounds 3, 5, 6 and 9) increased the $\log \mathrm{k}_{\mathrm{w}}$ values in a number: $\mathrm{CH}_{3}<\mathrm{Cl}<\mathrm{Br}<\mathrm{CF}_{3}$; wherein the differences in the values were insignificant. Introducing an additional substituent to the aromatic ring increased the value of $\log \mathrm{k}_{\mathrm{w}}$. The significant increase of the $\log \mathrm{k}_{\mathrm{w}}$ parameter was observed for the compound $\mathbf{7}$ with two chlorine atoms in the positions 2 and 4 of the aromatic ring and for the compound 2 with fluorine atom in the position 2 and bromine atom in the position 4 of the aromatic ring. The presence of two fluorine atoms at position 2 and 6 of the aromatic ring (compound 8) does not significantly affect the $\log \mathrm{k}_{\mathrm{w}}$ values in comparison with a molecule containing one fluorine atom in the position 2 (compound 4 ).

Relative lipophilicity $\log \mathrm{k}_{\mathrm{w}}$ values were compared with $\log \mathrm{P}$ values, calculated by computational methods using VCCLAB software ${ }^{20}$ (Table 2).

Experimental and calculated $\log \mathrm{P}$ values were used for 
Table 2. The comparison $\log \mathrm{k}_{\mathrm{w}}$ values of compounds 1-10 with $\log \mathrm{P}$ values calculated by computing programs

\begin{tabular}{lcccccccccc}
\hline & \multicolumn{10}{c}{ Compound } \\
\cline { 2 - 10 } & $\mathbf{1}$ & $\mathbf{2}$ & $\mathbf{3}$ & $\mathbf{4}$ & $\mathbf{5}$ & $\mathbf{6}$ & $\mathbf{7}$ & $\mathbf{8}$ & $\mathbf{9}$ & $\mathbf{1 0}$ \\
\hline $\log \mathrm{k}_{\mathrm{w}}$ methanol & 2.50 & 5.83 & 5.81 & 4.84 & 5.59 & 5.38 & 6.06 & 4.89 & 2.50 & 4.91 \\
$\log \mathrm{k}_{\mathrm{w}}$ isopropanol & 0.94 & 2.45 & 2.27 & 2.02 & 2.25 & 2.16 & 2.54 & 2.03 & 2.18 & 1.39 \\
$\log \mathrm{k}_{\mathrm{w}}$ acetonitrile & 1.60 & 4.57 & 3.62 & 3.16 & 3.45 & 3.38 & 3.75 & 3.21 & 3.31 & 3.18 \\
miLogP & 2.47 & 5.24 & 5.23 & 4.45 & 5.15 & 5.01 & 5.62 & 4.57 & 4.79 & 4.28 \\
XLOGP2 & 2.57 & 5.43 & 5.39 & 4.63 & 5.26 & 5.09 & 5.71 & 4.79 & 4.90 & 4.27 \\
XLOGP3 & 2.95 & 5.21 & 5.30 & 4.52 & 5.11 & 5.05 & 5.68 & 4.62 & 4.78 & 4.22 \\
ALOGPS & 2.56 & 4.92 & 5.05 & 4.44 & 4.70 & 5.07 & 5.43 & 4.42 & 4.80 & 3.91 \\
MLOGP & 1.60 & 4.36 & 4.20 & 3.74 & 3.97 & 3.86 & 4.36 & 4.12 & 3.59 & 3.09 \\
AC $\log$ PP & 3.42 & 5.48 & 5.49 & 4.78 & 5.42 & 5.34 & 5.95 & 4.84 & 5.04 & 4.49 \\
\hline
\end{tabular}

$\log \mathrm{k}_{\mathrm{w}}$ : lipophilicity parameter; $\log \mathrm{k}_{\mathrm{w}}$ is $\log \mathrm{k}$ value extrapolated to zero organic modifier concentration; miLogP, XLOGP2, XLOGP3, ALOGPS, MLOGP, $\mathrm{AC} \log \mathrm{P}$ are $\log \mathrm{P}$ values calculated by computing programs.

the analysis employing hierarchical cluster analysis (HCA) and principal component analysis (PCA). In this aim, the program Statistica 12 from StatSoft was used. Analyses were performed at a significance level $\alpha=0.05$.

In HCA, the Euclidian distance was selected as a measure of dissimilarity among the variables, and the Ward's method was used to define the distances among clusters (Figure 4).

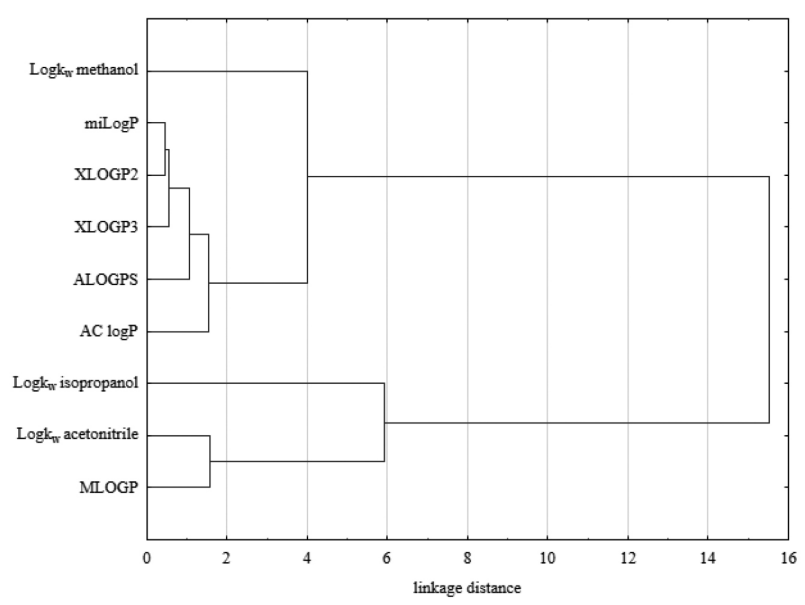

Figure 4. Hierarchical cluster analysis: a dendrogram showing grouping pattern (similarities) of different $\log \mathrm{P}$.

Data were grouped in the matrix and analyzed using PCA, based on the covariance matrix.

In the analysis, two factors were isolated and correspond to $97.22 \%$ of all the variables (PC1-87.53\%, PC2-9.69\%) (Figure 5). Additionally, the correlation matrix was made for $\log \mathrm{k}_{\mathrm{w}}$, miLogP, XLOGP2, XLOGP3, ALGPS, MLOGP and $\mathrm{AC} \log \mathrm{P}$ (Tables 3 and 4).

PCA and correlation studies clearly show all data are strongly positively correlated. The analyses showed that

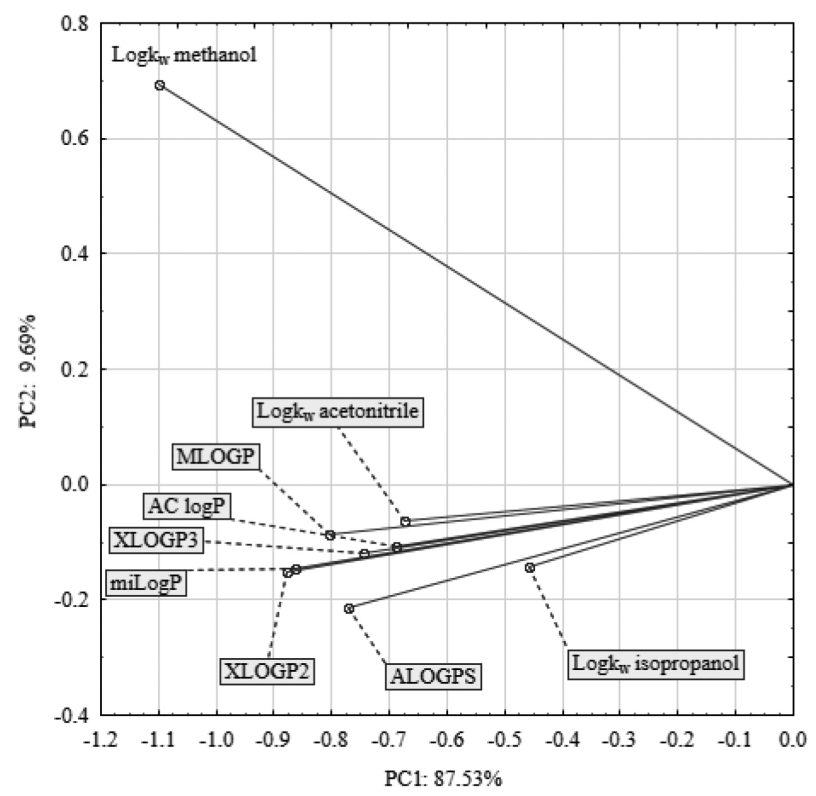

Figure 5. Data projection on the plane determined by two first principal components (PC1 vs. PC2).

all obtained results are similar. However, the weakest correlation with all the data shows $\log \mathrm{k}_{\mathrm{w}}$ in methanol.

\section{Conclusions}

In conclusion, lipophilicity parameters $\log \mathrm{k}_{\mathrm{w}}$ for the 1-(benzofuran-2-yl)ethan-1-one oxime and its nine biological active ethers using reversed phase HPLC method was determined. The values were compared with $\log \mathrm{P}$ values calculated by computing programs. Both experimental and calculated parameters are strongly positively correlated. The analyses showed that all obtained results are similar. However, the weakest correlation with all the data shows $\log \mathrm{k}_{\mathrm{w}}$ methanol. For all of analyzed compounds, $\log \mathrm{k}_{\mathrm{w}}$ 
Table 3. Pearson's correlations coefficients

\begin{tabular}{lccccccccc}
\hline & $\begin{array}{c}\log \mathrm{k}_{\mathrm{w}} \\
\text { methanol }\end{array}$ & $\begin{array}{c}\log \mathrm{k}_{\mathrm{w}} \\
\text { isopropanol }\end{array}$ & $\begin{array}{c}\log \mathrm{k}_{\mathrm{w}} \\
\text { acetonitrile }\end{array}$ & miLogP & XLOGP2 & XLOGP3 & ALOGPS & MLOGP & AC logP \\
\hline $\log \mathrm{k}_{\mathrm{w}}$ methanol & 1.000 & 0.636 & 0.722 & 0.743 & 0.743 & 0.749 & 0.668 & 0.760 & 0.746 \\
$\log \mathrm{k}_{\mathrm{w}}$ isopropanol & 0.636 & 1.000 & 0.865 & 0.945 & 0.961 & 0.959 & 0.959 & 0.946 & 0.959 \\
$\log \mathrm{k}_{\mathrm{w}}$ acetonitrile & 0.722 & 0.865 & 1.000 & 0.903 & 0.909 & 0.880 & 0.854 & 0.901 & 0.870 \\
miLogP & 0.743 & 0.945 & 0.903 & 1.000 & 0.997 & 0.993 & 0.979 & 0.955 & 0.986 \\
XLOGP2 & 0.743 & 0.961 & 0.909 & 0.997 & 1.000 & 0.993 & 0.979 & 0.971 & 0.985 \\
XLOGP3 & 0.749 & 0.959 & 0.880 & 0.993 & 0.993 & 1.000 & 0.983 & 0.948 & 0.997 \\
ALOGPS & 0.668 & 0.959 & 0.854 & 0.979 & 0.979 & 0.983 & 1.000 & 0.939 & 0.976 \\
MLOGP & 0.760 & 0.946 & 0.901 & 0.955 & 0.971 & 0.948 & 0.939 & 1.000 & 0.931 \\
AC $\log P$ & 0.746 & 0.959 & 0.870 & 0.986 & 0.985 & 0.997 & 0.976 & 0.931 & 1.000 \\
\hline
\end{tabular}

$\log \mathrm{k}_{\mathrm{w}}$ : lipophilicity parameter; $\log \mathrm{k}_{\mathrm{w}}$ is $\log \mathrm{k}$ value extrapolated to zero organic modifier concentration; miLogP, XLOGP2, XLOGP3, ALOGPS, MLOGP, $\mathrm{AC} \log \mathrm{P}$ are $\log \mathrm{P}$ values calculated by computing programs.

Table 4. Spearman's correlations coefficients

\begin{tabular}{lccccccccc}
\hline & $\begin{array}{c}\log \mathrm{k}_{\mathrm{w}} \\
\text { methanol }\end{array}$ & $\begin{array}{c}\log \mathrm{k}_{\mathrm{w}} \\
\text { isopropanol }\end{array}$ & $\begin{array}{c}\log \mathrm{k}_{\mathrm{w}} \\
\text { acetonitrile }\end{array}$ & miLogP & XLOGP2 & XLOGP3 & ALOGPS & MLOGP & AC logP \\
\hline $\log \mathrm{k}_{\mathrm{w}}$ methanol & 1.000 & 0.815 & 0.881 & 0.869 & 0.869 & 0.857 & 0.705 & 0.854 & 0.857 \\
$\log \mathrm{k}_{\mathrm{w}}$ isopropanol & 0.815 & 1.000 & 0.964 & 0.988 & 0.988 & 0.976 & 0.842 & 0.875 & 0.976 \\
$\log \mathrm{k}_{\mathrm{w}}$ acetonitrile & 0.881 & 0.964 & 1.000 & 0.976 & 0.976 & 0.952 & 0.818 & 0.875 & 0.952 \\
miLogP & 0.869 & 0.988 & 0.976 & 1.000 & 1.000 & 0.988 & 0.879 & 0.900 & 0.988 \\
XLOGP2 & 0.869 & 0.988 & 0.976 & 1.000 & 1.000 & 0.988 & 0.879 & 0.900 & 0.988 \\
XLOGP3 & 0.857 & 0.976 & 0.952 & 0.988 & 0.988 & 1.000 & 0.891 & 0.881 & 1.000 \\
ALOGPS & 0.705 & 0.842 & 0.818 & 0.879 & 0.879 & 0.891 & 1.000 & 0.705 & 0.891 \\
MLOGP & 0.854 & 0.875 & 0.875 & 0.900 & 0.900 & 0.881 & 0.705 & 1.000 & 0.881 \\
AC $\operatorname{logP}$ & 0.857 & 0.976 & 0.952 & 0.988 & 0.988 & 1.000 & 0.891 & 0.881 & 1.000 \\
\hline
\end{tabular}

$\log \mathrm{k}_{\mathrm{w}}$ : lipophilicity parameter; $\log \mathrm{k}_{\mathrm{w}}$ is $\log \mathrm{k}$ value extrapolated to zero organic modifier concentration; miLogP, XLOGP2, XLOGP3, ALOGPS, MLOGP, AC $\log \mathrm{P}$ are $\log \mathrm{P}$ values calculated by computing programs.

values are $<5$ in the case of using acetonitrile, and isopropanol as an organic modifier which corresponds to the Lipinski's rule in the range of lipophilicity. Not much higher than $5 \log \mathrm{k}_{\mathrm{w}}$ values obtained in the case of use of methanol indicate that the analyzed compounds are not lipophilic enough to impede their migration through the biological membranes. Therefore, we think that in the case of their use as drugs, the compounds will be active after oral application.

\section{Acknowledgments}

This work has been supported by Nicolaus Copernicus University, Collegium Medicum as part of statutory research project No. 473 (2016).

\section{References}

1. Arora, P.; Arora, V.; Lamba, H. S.; Wadhwa, D.; IJPSR 2012, 3, 2947.

2. Gomtsyan, A.; Chem. Heterocycl. Compd. 2012, 48, 7.
3. Nevagi, R. J.; Dighe, S. N.; Dighe, S. N.; Eur. J. Med. Chem. 2015, 97, 356.

4. Kamal, M.; Shakya, A. K.; Jawaid, T.; Int. J. Med. Pharm. Sci. 2011, 1,1 .

5. Chakravarti, B.; Akhtar, T.; Rai, B.; Yadav, M.; Akhtar Siddiqui, J.; Dhar Dwivedi, S. K.; Thakur, R.; Singh, A. K.; Singh, A. K.; Kumar, H.; Khan, K.; Pal, S.; Rath, S. K.; Lal, J.; Konwar, R.; Trivedi, A. K.; Datta, D.; Mishra, D. P.; Godbole, M. M.; Sanyal, S.; Chattopadhyay, N.; Kumar, A.; J. Med. Chem. 2014, 57, 8010.

6. Ozdemir, Z.; Karakurt, A.; Calis, U.; Gunal, S.; Isik, S.; Sahin, Z. S.; Dalkara, S. J.; J. Med. Chem. 2015, 11, 41.

7. Bhandari, K.; Srinivas, N.; Shiva Keshava, G. B.; Shukla, P. K.; Eur. J. Med. Chem. 2009, 44, 437.

8. Abid, M.; Husain, K.; Azam, A.; Bioorg. Med. Chem. Lett. 2005, 15,4375 .

9. Dai, H.; Chen, J.; Li, H.; Dai, B; He, H.; Fang, Y.; Shi, Y.; Molecules, 2016, 21, 276.

10. Gundogdu, K. N.; Benkli, K.; Tunali, Y.; Ucucu, U.; Demirayak, S.; Eur. J. Med. Chem. 2006, 41, 651. 
11. Kilirmiş, C.; Koca, M.; Servi, S.; Gür, S.; Turk. J. Chem. 2009, 33,375 .

12. Kirilmis, C.; Koca, M.; Çukurovali, A.; Ahmedzade, M.; Kazaz, C.; Molecules 2005, 10, 1399.

13. Kosmalski, T.; Kutkowska, J.; Gzella, A. K.; Nowakiewicz, A.; Acta Pol. Pharm. 2015, 72, 289.

14. Zejc, A.; Gorczyca, M.; Drugs Chemistry; Wydawnictwo Lekarskie PZWL: Warszawa, Poland, 2002.

15. Lipinski, C. A.; Lombardo, F.; Dominy, B. W.; Feeney, P. J.; Adv. Drug Delivery Rev. 2012, 64, 4.

16. Jóźwiak, K.; Szumiło, H.; Soczewiński, E.; Wiadomości Chemiczne 2001, 55, 1047 (in Polish).

17. Studzińska, R.; Kołodziejska, R.; Redka, M.; ModzelewskaBanachiewicz, B.; J. Braz. Chem. Soc. 2016, 27, 1587.
18. Hawrył, A. M.; Popiołek, Ł. P.; Hawrył, M. A.; Świeboda, R. S.; Niejedli, M. A.; J. Braz. Chem. Soc. 2015, 8, 1617.

19. Valko, K.; Slegel, P. J.; J. Chromatogr. 1993, 631, 49.

20. Tetko, I. V.; Gasteiger, J.; Todeschini, R.; Mauri, A.; Livingstone, D.; Ertl, P.; Palyulin, V. A.; Radchenko, E. V.; Zefirov, N. S.; Makarenko, A. S.; Tanchuk, V. Y.; Prokopenko, V. V.; J. Comput.-Aided Mol. Des. 2005, 19, 453; VCCLAB, Virtual Computational Chemistry Laboratory, http://www. vcclab.org, 2005, accessed in March 2017.

Submitted: January 5, 2017

Published online: March 24, 2017 